\title{
Antimicrobial susceptibility profiles, serotype distribution and virulence determinants among invasive, non-invasive and colonizing Streptococcus agalactiae (group B streptococcus) from Malaysian patients
}

\author{
N. Eskandarian • Z. Ismail • V. Neela • A. van Belkum • \\ M. N. M. Desa • S. Amin Nordin
}

Received: 10 June 2014 / Accepted: 8 October 2014 / Published online: 31 October 2014

(C) The Author(s) 2014. This article is published with open access at Springerlink.com

\begin{abstract}
A total of 103 group B streptococci (GBS) including 22 invasive, 21 non-invasive, and 60 colonizing isolates were collected in a Malaysian hospital (June 2010-October 2011). Isolates were characterized by conventional and molecular serotyping and analyzed for $s c p B, \operatorname{lmb}$, hylB, $c y l E, b a c$, $b c a$ and $r i b$ gene content. Antimicrobial susceptibility to penicillins, macrolides, lincosamides, quinolones and tetracyclines was determined using disk diffusion and the MICs for penicillin were determined by E-test. Molecular serotyping for all eight serotypes (Ia, Ib, II-VII) was in full accordance with conventional serotyping. Overall, taking CS and MS together, serotype VI was the most common capsular type (22.3\%) followed by VII (21.4\%), III (20.4 \%), Ia (17.5\%), V (9.7\%), II (7.7 \%) and IV (1\%). Susceptibility to beta-lactam antimicrobials was prevalent (100\%). Resistance rates for erythromycin, clindamycin and tetracycline were $23.3 \%, 17.5 \%$ and $71.8 \%$, respectively. PCR-virulence gene screening showed the presence of $c y l E, \operatorname{lmb}, s c p B$ and $h y l B$ in almost all the
\end{abstract}

N. Eskandarian $\cdot$ V. Neela $\cdot$ S. Amin Nordin $(\bowtie)$

Department of Medical Microbiology and Parasitology, Faculty of

Medicine and Health Sciences, Universiti Putra Malaysia,

43400 Serdang, Selangor, Malaysia

e-mail: syafinaz@upm.edu.my

Z. Ismail

Department of Medical Microbiology and Immunology, Faculty of Medicine, Universiti Kebangsaan Malaysia, 56000 Cheras,

Kuala Lumpur, Malaysia

A. van Belkum

bioMérieux R\&D Microbiology, La Balme Les Grottes 38390, France

M. N. M. Desa

Department of Biomedical Sciences, Faculty of Medicine and Health Sciences, Universiti Putra Malaysia, 43400 Serdang, Selangor, Malaysia isolates while $r i b, b c a$, and $b a c$ genes were found in $29.1 \%$, $14.6 \%$ and $9.7 \%$ of the isolates. Certain genes were significantly associated with specific serotypes, namely, rib with serotypes Ia, II, III and VI; $b c a$ and $b a c$ with serotypes II and III. Furthermore, serotype Ia was significantly more common among patients with invasive infections $(p<0.01)$ and serotype VI isolates were significantly more common among carriers $(p<0.05)$. In summary, serotype distribution correlates with virulence gene content will be useful in epidemiological studies and design of vaccines.

\section{Introduction}

Streptococcus agalactiae, the group B streptococcus (GBS), is a gram-positive and encapsulated bacterium, which displays beta-hemolytic activity on blood agar. It is part of the commensal flora in the genital and lower gastrointestinal tracts in $10-40 \%$ of healthy adults [1]. However, vaginal colonization by GBS during pregnancy may be clinically significant because it is associated with neonatal meningitis and septicemia [2]. During recent decades, GBS infection has increasingly emerged in adults, particularly those with underlying illness such as diabetes [3].

Penicillin is the first-line agent for prevention and treatment of GBS infections [1, 4]; however, since 1994, GBS isolates with reduced susceptibility to penicillin have been reported periodically [5]. In case of penicillin allergy, clindamycin and erythromycin are the most recommended alternatives. Consequently, the increasing use of these drugs, consumed by around $20 \%$ of all GBS carriers, resulted in elevated rates of clindamycin and erythromycin resistance worldwide $[6,7]$. Capsular serotype contributes to disease severity and defines vaccine development [8]. Ten GBS capsular types have been 
identified (Ia, Ib and II-IX) and vaccination against five serotypes (Ia, Ib, II, III and V) is in development [7, 9]. Several investigations revealed that strains harboring the CPS types Ia, II, III, and V are the most significant causes of GBS invasive disease in neonates and other patients $[10,11]$. PCR can identify serologically non-typable strains since these generally still carry the required genes [12]. Therefore, molecular serotyping techniques have an elevated discriminatory power for epidemiological studies [13].

GBS has many virulence factors including surface proteins, toxins and hydrolytic enzymes [14]. Surface proteins mostly function as adhesins, which may also contribute to immune evasion. These include $\mathrm{C} 5 \mathrm{a}$ peptidase ( $\mathrm{ScpB}$ ), lamininbinding protein $(\mathrm{Lmb})$, the $\alpha$ and $\beta$-subunits of $\mathrm{C}$ protein (Bca and Bac) and Rib protein. GBS secrete a variety of toxins such as $\beta$-hemolysin/cytolysin (cylE), hyaluronidase (hylE) and the CAMP factor (cfb) which facilitate entry of GBS into host cells and promote its intra-cellular survival [15].

Epidemiological studies on GBS, assessment of their antibiotic susceptibility and conventional serotyping are sparse in Malaysia. Molecular serotyping and virulence determinants of Malaysian GBS are published for the first time in this study.

\section{Materials and methods}

\section{Bacterial isolates}

A total of 103 pure cultures of GBS were obtained from outpatients and inpatients at the Universiti Kebangsaan Malaysia Medical Centre (UKMMC), a 900-bed teaching and referral hospital in Malaysia (June 2010-October 2011). Isolates were grouped into three different types based on the clinical outcome and site of isolation: invasive $(n=22)$ for isolates derived from normally sterile body site such as blood; non-invasive isolates $(n=21)$ for isolates derived from wound and skin ulcers, tracheal and gastric aspirates; colonizing isolates $(n=60)$ derived from vaginal swabs and urine samples from asymptomatic patients. Basically, pure GBS cultures were obtained except for $10(9.7 \%)$ cases in which GBS coexisted with other organisms (e.g. Staphylococcus aureus, coagulase-negative staphylococci, Escherichia coli, Pseudomonas aeruginosa, Klebsiella species or unspecified gram positive and negative cocci). Identification was carried out based on culture characteristics, Gram staining, catalase testing and CAMP testing. The species nature of the isolates was confirmed by slide agglutination using Streptex (Murex Diagnostics, UK) and by conventional PCR assays targeting the $c f b$ gene (encoding the CAMP factor). All strains were preserved in sterile nutrient broth with $15 \%$ glycerol and on beads in cryo-vials (Pro-Lab, UK) at $-70{ }^{\circ} \mathrm{C}$ for long-term storage and on $5 \%$ sheep blood agar plates at $4{ }^{\circ} \mathrm{C}$ for short-term maintenance.

\section{Serotyping}

Capsular serotyping was performed by the latex agglutination method using antisera specific for each capsular type (Ia, Ib, II-VII) using Strep-B-Latex kits (Statens Serum Institute, SSI, Sweden). Isolates that did not react with any of the antisera were classified as serologically non-typeable (NT). Further confirmation of capsular types was performed for all strains using PCR. The conventional PCR assay as developed for seven GBS capsular types (Ia-VII) and targeting the cps gene cluster was used according to Borchardt et al. [16]. DNA was extracted using GeneAll Exgene Mini genomic extraction kits (GeneAll, South Korea) following the manufacturer's instructions. The GBS reference strains A909 (type Ia), H36B (type Ib), 18RS21 (type II), M78 (type III), CNCTC 1/82 (type IV), BAA-611 (type V), NT6 (type VI), 7271 SSI (type VII) were kindly provided by Universiti Kebangsaan Malaysia Medical Centre.

Antimicrobial susceptibility testing

Antibiotic susceptibility testing (AST) was performed by the disc diffusion (Kirby-Bauer) method according to the guidelines described by CLSI in 2012 [17]. The panel of antibiotics included penicillins (penicillin $\mathrm{G}$ and ampicillin), cephalosporins (cefuroxime and ceftriaxone), a quinolone (levofloxacin), a glycopeptide (vancomycin), a macrolide (erythromycin), a lincosamide (clindamycin), a phenicole (chloramphenicol) and tetracycline. The MIC for penicillin was determined using the Etest ${ }^{\circledR}$ strip (bioMérieux, Marcy l'Etoile, France). Each batch of tests was run concurrently with Streptococcus pneumoniae ATCC 49619 as quality control. The diameters of the inhibition zones and MICs were interpreted based on CLSI interpretation guidelines (2012) [17]. Erythromycin resistant, clindamycin sensitive strains were further tested by the double-disc diffusion method (D-zone test) with erythromycin and clindamycin disks $12 \mathrm{~mm}$ apart. Strains with D-shaped clindamycin zones (inducible clindamycin resistance) were considered as "clindamycin resistant".

\section{Determination of virulence genes}

All GBS isolates were screened for the presence of seven virulence genes, namely, $s c p B$, lmb, hylB, $c y l E, b a c, b c a$ and $r i b$ encoding $\mathrm{C} 5 \mathrm{a}$ peptidase, laminin binding protein, hyaluronate lyase, $\beta$-hemolysin/cytolysin, $\beta$-C protein, $\alpha$-C protein and Rib protein by using PCR. The oligonucleotide primers and PCR cycling conditions were as reported by others [18-21]. The GBS reference strains, ATCC 13813 (cfb), ATCC BAA-611 (rib), NCTC 11078 (bca, and bac), ATCC 12403 (cylE), ATCC 12386 (lmb and scpB) and Streptococcus agalactiae, strain 4755 (hylB), were included as positive controls. 
Statistical analysis

The SPSS statistical analysis package (version 21.0 for Windows) was used to analyze the significance of the results. Chisquare tests of independence were performed to assess possible associations between the variables. The significance level was set at $p<0.05$. If the chi-square test of independence was statistically significant, then post-hoc comparison tests were conducted to determine the variable that produced the statistically most significant difference. The obtained standard residual (std.res) from post-hoc analysis was considered significant when std.res $>1.96,>2.58$ and $>3.33$ were at $0.05,0.01$ and 0.001 level of significance.

\section{Results}

Clinical data of all patients are summarized in Table 1. Among the 103 GBS isolates, $11(10.7 \%)$ were from neonates, all of whom presented with early-onset disease ( $<7$ days old) and more than half of the neonates (64\%) were known to have GBS bacteremia. Ninety-two isolates $(89.3 \%)$ were recovered from adults (age range 20-87). In non-pregnant adults ( $n=43$ ), GBS isolates were often isolated from blood (37.3\%), vagina (35\%), wound and abscess specimens (26\%). Urine sample yielded only one isolate (1.7\%). Among pregnant women, most of the GBS isolates were recovered from vaginal specimens $(90 \%)$. Blood, urine and placenta swabs yielded a few additional isolates $(10 \%)$.

Comparison of conventional serotyping (CS) with molecular serotyping (MS)

CS was able to identify the capsular serotypes of $80.6 \%$ $(83 / 103)$ of the GBS isolates studied and 20 (19.4\%) isolates remained non-typable. All GBS isolates were also tested by MS in order to confirm the accuracy of CS. MS was in accordance with CS for the CS-typeable isolates. MS was able to detect capsular serotype genes in all 20 (19.4\%) serologically non-typable isolates. Six isolates showed serotype III while the remaining 14 isolates were of serotype VII. Overall, taking CS and MS together, serotype VI was the most common capsular type $(n=23,22.3 \%)$ followed by VII $(n=22,21.4 \%)$, III $(n=21,20.4 \%)$, Ia $(n=18$, $17.5 \%), \mathrm{V}(n=10,9.7 \%), \mathrm{II}(n=8,7.7 \%)$ and IV $(n=1$, $1 \%$ ). No serotype Ib isolates were found in the present study.

Antimicrobial susceptibility profiles

All GBS strains were susceptible to penicillin G, ampicilin, cefuroxime, ceftriaxone, levofloxacin, vancomycin and chloramphenicol. A hundred percent susceptibility to penicillin was also confirmed by E-test where the MIC ranged from 0.023 to $0.064 \mu \mathrm{g} / \mathrm{ml}$. The AST results showed that the majority of isolates ( $n=74,71.8 \%$ ) were resistant to tetracycline. Twenty-four isolates $(23.3 \%)$ were resistant to erythromycin and $18(17.5 \%)$ to clindamycin. Only one case of the 18 resistant isolates showed inducible clindamycin resistance.

PCR amplification of the virulence genes

All isolates were positive for the $c f b$ gene, which helped to confirm the species identity of GBS. Genes encoding the $\boldsymbol{\beta}$ hemolysin/cytolysin $(\beta \mathrm{H} / \mathrm{C})$, laminin binding protein, $\mathrm{C} 5 \mathrm{a}$ peptidase, and hyaluronate lyase $(c y l E, \operatorname{lmb}, \operatorname{scpB}$ and $h y l B)$ were present in $97.1 \%, 97.1 \%, 96.1 \%$ and $94.2 \%$ of isolates, respectively, making them the predominant virulence genes. The $r i b, b c a$, and $b a c$ genes were found in $29.1 \%, 14.6 \%$ and $9.7 \%$ of the isolates, respectively.

Association of genotypic traits with molecular serotyping

The distribution of three genotypic traits (bac, bca, rib) and various serotypes are presented in Table 2. As $c y l E, \operatorname{lmb}, s c p B$, $h y l B$ were detected in almost all GBS isolates $(97.1 \%$, $97.1 \%, 96.1 \%, 94.2 \%$, respectively), these were excluded from the analysis. Serotype IV was detected only once and was also excluded. The rib gene is significantly associated with serotype Ia, VI $(p<0.05)$, II and III $(p<0.01)$. The $b c a$ gene was more common among serotype II $(p<0.001)$ and III $(p<0.01)$ strains. A significant association was also found between the bac gene and serotype II $(p<0.001)$ and III $(p<0.05)$ (Table 2).

Table 1 Distribution of 103 GBS isolates among patient groups

\begin{tabular}{lllll}
\hline Patient group & $\begin{array}{l}\text { No. (\%) of } \\
\text { patients }\end{array}$ & $\begin{array}{l}\text { Invasive } \\
\text { population }\end{array}$ & $\begin{array}{l}\text { Non-invasive } \\
\text { population }\end{array}$ & $\begin{array}{l}\text { Colonizing } \\
\text { population }\end{array}$ \\
\hline Neonate & $11(10.7)$ & 7 & 4 & 0 \\
Pregnant adults & $49(47.6)$ & 0 & 3 & 46 \\
Non-pregnant adults & $43(41.7)$ & 15 & 14 & 14 \\
Total & $103(100)$ & 22 & 21 & 60 \\
\hline
\end{tabular}


Table 2 Association between capsular serotype and virulence genes in 103 isolates of group B streptococcus

\begin{tabular}{|c|c|c|c|c|c|c|}
\hline Serotype & $r i b^{+}$ & $p$-value & $b_{c a}^{+}$ & $p$-value & $b a c^{+}$ & $p$-value \\
\hline Ia & $1(5.0 \%)$ & $<0.05$ & $0(0.0 \%)$ & $>0.05$ & $0(0.0 \%)$ & $>0.05$ \\
\hline II & $7(87.5 \%)$ & $<0.01$ & $7(87.5 \%)$ & $<0.001$ & $5(62.5 \%)$ & $<0.001$ \\
\hline III & $12(63.2)$ & $<0.01$ & $8(42.1 \%)$ & $<0.001$ & $5(26.3 \%)$ & $<0.01$ \\
\hline $\mathrm{V}$ & $3(37.5 \%)$ & $>0.05$ & $0(0.0 \%)$ & $>0.05$ & $0(0.0 \%)$ & $>0.05$ \\
\hline VI & $2(7.7 \%)$ & $<0.05$ & $0(0.0 \%)$ & $>0.05$ & $0(0.0 \%)$ & $>0.05$ \\
\hline VII & $5(23.8 \%)$ & $>0.05$ & $0(0.0 \%)$ & $>0.05$ & $0(0.0 \%)$ & $>0.05$ \\
\hline Total & $30(29.4)$ & & $15(14.7 \%)$ & & $10(9.8 \%)$ & \\
\hline
\end{tabular}

$r i b+, b c a+$ and $b a c+$ indicates presence of $r i b, b c a$ and $b a c$ genes

std. res $>1.96, p<0.05$

std. res $>2.58, p<0.01$

std. res $>3.33, p<0.001$

Although all serotypes were observed among the three populations studied, serotype Ia was significantly more common among patients with invasive infections $(p<0.01)$ and serotype VI isolates were significantly more common among carriers $(p<0.05)$ (Table 3$)$.

No statistically significant associations were found between the virulence genes and the isolate status or age of patients in the present study $(p>0.05)$.

\section{Discussion}

In Malaysia, data on detection of GBS virulence genes and molecular serotyping are non-existent. In the present research, GBS isolates were serotyped by both phenotypic and genotypic approaches and further characterized for their virulence patterns and antibiotic susceptibility profiles.

Serotype distribution of GBS isolates has previously been reported to vary geographically $[9,22]$. In the present study, MS results showed serotype VI (22.2\%) to be overrepresented in the Malaysian population. In contrast, an older study found lower numbers of serotype VI isolates among adults and

Table 3 Distribution of the serotypes within the studied GBS populations

\begin{tabular}{llll}
\hline Serotype & $\begin{array}{l}\text { Invasive } \\
\text { population }\end{array}$ & $\begin{array}{l}\text { Non-invasive } \\
\text { population }\end{array}$ & $\begin{array}{l}\text { Colonizing } \\
\text { population }\end{array}$ \\
\hline Ia & $10(45.5)^{* *}$ & $6(28.6)$ & $2(3.4)$ \\
II & $1(4.5)$ & $0(0.0)$ & $7(11.8)$ \\
III & $2(9.1)$ & $4(19.0)$ & $15(25.0)$ \\
V & $1(4.5)$ & $2(9.5)$ & $7(11.8)$ \\
VI & $3(13.7)$ & $3(14.3)$ & $17(30.0)^{*}$ \\
VII & $5(22.7)$ & $6(28.6)$ & $11(18.0)$ \\
\hline
\end{tabular}

${ }^{*} p<0.05,{ }^{*} p<0.01$ neonates [23]. Serotype VII is rarely reported worldwide [7, 24, 25]; however, we found a relatively high number of strains with serotype VII ( $n=22,21.3 \%$ ) among Malaysians. Only eight GBS isolates from our study were CPS type II while a cross-sectional study in South East Asia reported this type as predominant among pregnant women [22]. Serotype Ia was significantly more common among patients with invasive infections $(p<0.01)$ and serotype VI isolates were significantly more common among carriers $(p<0.05)$. All isolates were typable by MS, while a considerable proportion (19.4\%) of isolates could not be typed by $\mathrm{CS}$, as also observed in previous studies [9, 26, 27].

The overall beta-lactam susceptibility of Malaysian GBS was confirmed here [1, 4, 22]. Neither penicillin-resistant nor penicillin intermediate GBS strains were detected. Some investigations have identified GBS isolates with reduced sensitivity [5, 28, 29]. Hence, penicillin could still be used as a firstline drug for intra-partum prophylaxis and treatment of GBS infections in Malaysia.

The rates of resistance to erythromycin and clindamycin were lower than those in the studies from Japan, Europe and the United States [30, 31], but can be considered high in comparison to the studies from Asian countries [32, 33]. The resistance documented for erythromycin and clindamycin provides a warning that these drugs need to be prescribed with care since also non-susceptible GBS were observed in the United States and Japan [28, 34].

The frequency of virulence gene rib presence is similar to other studies from Europe, the United States and Lebanon [15, 18,35 ] and higher than those reported among pregnant women in Poland and Kuwait [14, 36]. The bca encodes $\boldsymbol{\alpha}-\mathrm{C}$ surface protein (ACP) was observed in a lower frequency than in previous reports, where its presence varied from 42 to $85 \%$ $[15,36,37]$. Another study has identified the bca gene in $100 \%$ of strains; however, in this case only potentially clonal type Ia strains were tested [38]. The bac gene was found at a lower frequency $(9.7 \%)$ as compared to other studies from the 
United States, Europe and New Zealand [7, 18, 39]. A recent study among pregnant women in Kuwait detected $b a c$ in only $3.2 \%$ of isolates [37].

Certain virulence genes were significantly more prevalent in given CPS types. For instance, rib was associated significantly with serotypes Ia, II, III and VI. Previous data from South East Asian countries and Europe confirmed the association between $r i b$ gene and serotype Ia, II and III [39-42]. Moreover, our results indicated a significant association between serotypes II and III with $b c a$ and $b a c$, while other studies demonstrated association between $b c a$ and $b a c$ with serotype Ib and II [35, 39, 41]. According to Duarte et al. (2005) around 30$55 \%$ of serotype Ia GBS isolates in humans harbored the $b c a$ gene [20]. In another study reported by Dore et al. around $50 \%$ of serotype III isolates harbored the $b c a$ or $b a c$ or both [42]. This difference may be caused by geographical differences in prevalence or may indicate the appearance of silent $b c a$ and $b a c$ genes in these serotypes.

The present study could not demonstrate any correlation between the virulence genes and clinical status of the patients from whom the isolates were obtained $(p>0.05)$; however, as pointed out by Maning et al. invasive isolates showed a tendency to have $r i b$ and $b a c$ [18]. No significant associations were found between the occurrence of virulence genes and the age of patients in the present study $(p>0.05)$. However, based on data presented by Ho et al. the majority of $b c a$ genes $(85.4 \%)$ in GBS isolates were observed in strains from adults, whereas $59.2 \%$ of $r i b$ gene was harbored among isolates from neonates [40]. Given the lack of correlation we describe above, our data do not confirm the virulence potential of the genes detected.

In conclusion, our GBS collection contained a high number of strains with serotypes VI and VII, in contrast to findings in other countries [7, 24, 43]. Such differences in the relative regional incidence of serotypes could compromise the efficacy of vaccine. Additionally, the present study clearly shows the equivalence of MS and CS and indicates the broader coverage of MS. Data presented here confirms previous findings on the relationship between different virulence genes and serotypes but fails to confirm the virulence contribution of the panel of potential virulence genes we screened for.

Acknowledgments This research was supported by funding (ERGS 5527167) of the Ministry of Education, Malaysia. Ethical approval for the research has been provided by the Medical Research Ethics Committee of the Faculty of Medicine and Health Sciences, Universiti Putra Malaysia. The authors acknowledge the authorities and staff members of the Department of Medical Microbiology and Parasitology, Faculty of Medicine and Health Sciences, Universiti Putra Malaysia for their assistance as well as the members of Medical Microbiology and Immunology Laboratory, University Kebangsaan Malaysia Medical Centre (UKMMC) for their cordial assistance during sample collection.
Conflict of interest The authors declare that they have no conflict of interest.

Open Access This article is distributed under the terms of the Creative Commons Attribution License which permits any use, distribution, and reproduction in any medium, provided the original author(s) and the source are credited.

\section{References}

1. Dhanoa A, Karunakaran R, Puthucheary S (2010) Serotype distribution and antibiotic susceptibility of group B streptococci in pregnant women. Epidemiol Infect 138(07):979-981

2. Chattopadhyay D, Carey AJ, Caliot E, Webb RI, Layton JR, Wang Y, Bohnsack JF, Adderson EE, Ulett GC (2011) Phylogenetic lineage and pilus protein Spb1/SAN1518 affect opsonin-independent phagocytosis and intracellular survival of group B streptococcus. Microbes Infect 13(4):369-382

3. Eskandarian N, Neela V, Ismail Z, Puzi S, Hamat R, Desa M, Nordin S (2013) Group B streptococcal bacteremia in a major teaching hospital in Malaysia: a case series of eighteen patients. Int J Infect Dis 17:e777-e780

4. Karunakaran R, Raja NS, Hafeez A, Puthucheary SD (2009) Group B streptococcus infection: epidemiology, serotypes, and antimicrobial susceptibility of selected isolates in the population beyond infancy (excluding females with genital tract-and pregnancy-related isolates) at the University Malaya Medical Centre, Kuala Lumpur. Jpn J Infect Dis 62(3): 192-194

5. Longtin J, Vermeiren C, Shahinas D, Tamber GS, McGeer A, Low DE, Katz K, Pillai DR (2011) Novel mutations in a patient isolate of Streptococcus agalactiae with reduced penicillin susceptibility emerging after long-term oral suppressive therapy. Antimicrob Agents Chemother 55(6):2983-2985

6. Savoia D, Gottimer C, Crocilla C, Zucca M (2008) Streptococcus agalactiae in pregnant women: Phenotypic and genotypic characters. J Infect 56(2):120-125

7. Sadowy E, Matynia B, Hryniewicz W (2010) Population structure, virulence factors and resistance determinants of invasive, noninvasive and colonizing Streptococcus agalactiae in Poland. J Antimicrob Chemother 65(9):1907-1914

8. Zhao Z, Kong F, Zeng X, Gidding H, Morgan J, Gilbert G (2008) Distribution of genotypes and antibiotic resistance genes among invasive Streptococcus agalactiae (group B streptococcus) isolates from Australasian patients belonging to different age groups. Clin Microbiol Infect 14(3):260-267

9. Madzivhandila M, Adrian PV, Cutland CL, Kuwanda L, Schrag SJ, Madhi SA (2011) Serotype distribution and invasive potential of group B streptococcus isolates causing disease in infants and colonizing maternal-newborn dyads. PLoS One 6(3):e17861

10. Edmond KM, Kortsalioudaki C, Scott S, Schrag SJ, Zaidi AK, Cousens S, Heath PT (2012) Group B streptococcal disease in infants aged younger than 3 months: systematic review and meta-analysis. Lancet 379(9815):547-556

11. Gherardi G, Imperi M, Baldassarri L, Pataracchia M, Alfarone G, Recchia S, Orefici G, Dicuonzo G, Creti R (2007) Molecular epidemiology and distribution of serotypes, surface proteins, and antibiotic resistance among group B streptococci in Italy. J Clin Microbiol 45(9):2909-2916

12. Zhao Z, Kong F, Martinez G, Zeng X, Gottschalk M, Gilbert GL (2006) Molecular serotype identification of Streptococcus agalactiae of bovine origin by multiplex PCR-based reverse line blot (mPCR/RLB) hybridization assay. FEMS Microbiol Lett 263(2): 236-239 
13. Kong F, Ma L, Gilbert GL (2005) Simultaneous detection and serotype identification of Streptococcus agalactiae using multiplex PCR and reverse line blot hybridization. J Med Microbiol 54(12):11331138

14. Udo E, Boswihi S, Al-Sweih N (2013) Genotypes and virulence genes in group B streptococcus isolated in the maternity hospital, Kuwait. Med Princ Pract 22(5):453-457

15. Hannoun A, Shehab M, Khairallah M-T, Sabra A, Abi-Rached R, Bazi T, Yunis KA, Araj GF, Matar GM (2010) Correlation between group B streptococcal genotypes, their antimicrobial resistance profiles, and virulence genes among pregnant women in Lebanon. Int $\mathrm{J}$ Microbiol 2009:1-6

16. Borchardt SM, Foxman B, Chaffin DO, Rubens CE, Tallman PA, Manning SD, Baker CJ, Marrs CF (2004) Comparison of DNA dot blot hybridization and lancefield capillary precipitin methods for group B streptococcal capsular typing. J Clin Microbiol 42(1):146-150

17. Cockerill F (2012) Performance standards for antimicrobial susceptibility testing: twenty-second informational supplement. Clinical and Laboratory Standards Institute, Wayne, PA

18. Manning SD, Ki M, Marrs CF, Kugeler KJ, Borchardt SM, Baker CJ, Foxman B (2006) The frequency of genes encoding three putative group B streptococcal virulence factors among invasive and colonizing isolates. BMC Infect Dis 6(1):116

19. Bergseng H, Bevanger L, Rygg M, Bergh K (2007) Real-time PCR targeting the sip gene for detection of group B Streptococcus colonization in pregnant women at delivery. J Med Microbiol 56(2): 223-228

20. Duarte RS, Bellei BC, Miranda OP, Brito MA, Teixeira LM (2005) Distribution of antimicrobial resistance and virulence-related genes among Brazilian group B streptococci recovered from bovine and human sources. Antimicrob Agents Chemother 49(1):97-103

21. Sukhnanand S, Dogan B, Ayodele MO, Zadoks RN, Craver MPJ, Dumas NB, Schukken YH, Boor KJ, Wiedmann M (2005) Molecular subtyping and characterization of bovine and human Streptococcus agalactiae isolates. J Clin Microbiol 43(3):1177-1186

22. Turner C, Turner P, Po L, Maner N, De Zoysa A, Afshar B, Efstratiou A, Heath PT, Nosten F (2012) Group B streptococcal carriage, serotype distribution and antibiotic susceptibilities in pregnant women at the time of delivery in a refugee population on the ThaiMyanmar border. BMC Infect Dis 12(1):34

23. Ngeow Y, Puthucheary S (1987) Distribution of group B streptococcal serotypes in Malaysia. J Trop Med Hyg 90(4):193-196

24. Palmeiro JK, Dalla-Costa LM, Fracalanzza SE, Botelho AC, da Silva NK, Scheffer MC, de Almeida Torres RS, de Carvalho NS, Cogo LL, Madeira HM (2010) Phenotypic and genotypic characterization of group B streptococcal isolates in southern Brazil. J Clin Microbiol 48(12):4397-4403

25. Usein C-R, Grigore L, Georgescu R, Cristea V, Baltoiu M, Straut M (2012) Molecular characterization of adult-colonizing Streptococcus agalactiae from an area-based surveillance study in Romania. Eur J Clin Microbiol Infect Dis 31(9):2301-2310

26. Imperi M, Pataracchia M, Alfarone G, Baldassarri L, Orefici G, Creti R (2010) A multiplex PCR assay for the direct identification of the capsular type (Ia to IX) of Streptococcus agalactiae. J Microbiol Methods 80(2):212-214

27. Zeng X, Kong F, Morgan J, Gilbert GL (2006) Evaluation of a multiplex PCR-based reverse line blot-hybridization assay for identification of serotype and surface protein antigens of Streptococcus agalactiae. J Clin Microbiol 44(10):3822-3825

28. Dahesh S, Hensler ME, Van Sorge NM, Gertz RE, Schrag S, Nizet V, Beall BW (2008) Point mutation in the group B streptococcal $p b p 2 x$ gene conferring decreased susceptibility to $\boldsymbol{\beta}$-lactam antibiotics. Antimicrob Agents Chemother 52(8):2915-2918

29. Nagano N, Nagano Y, Kimura K, Tamai K, Yanagisawa H, Arakawa Y (2008) Genetic heterogeneity in pbp genes among clinically isolated group B streptococci with reduced penicillin susceptibility. Antimicrob Agents Chemother 52(12):4258-4267

30. Castellano-Filho DS, Silva VL, Nascimento TC, Vieira MT, Diniz CG (2010) Detection of group B streptococcus in Brazilian pregnant women and antimicrobial susceptibility patterns. Braz J Microbiol 41(4): 1047-1055

31. Lambiase A, Agangi A, Del Pezzo M, Quaglia F, Testa A, Rossano F, Martinelli P, Catania MR (2012) In vitro resistance to macrolides and clindamycin by group $\mathrm{B}$ streptococcus isolated from pregnant and nonpregnant women. Infect Dis Obstet Gynecol 2012:923603

32. Doran KS, Nizet V (2004) Molecular pathogenesis of neonatal group B streptococcal infection: no longer in its infancy. Mol Microbiol 54(1):23-31

33. Verani JR, McGee L, Schrag SJ (2010) Prevention of perinatal group B streptococcal disease. Morbidity and Mortality Weekly Report (MMWR), Revised Guidelines from CDC, Recommendations and Reports 59 (RR10):1-32

34. Kimura K, Suzuki S, J-i W, Kurokawa H, Yamane K, Shibata N, Nagano N, Kato H, Shibayama K, Arakawa Y (2008) First molecular characterization of group B streptococci with reduced penicillin susceptibility. Antimicrob Agents Chemother 52(8):2890-2897

35. Brzychczy-Wloch M, Gosiewski T, Bodaszewska-Lubas M, Adamski P, Heczko P (2012) Molecular characterization of capsular polysaccharides and surface protein genes in relation to genetic similarity of group B streptococci isolated from Polish pregnant women. Epidemiol Infect 140(02):329-336

36. Lysakowska ME, Kalinka J, Bigos M, Prosniewska M, Wasiela M (2011) Occurrence of virulence genes among $S$. agalactiae isolates from vagina and anus of pregnant women-a pilot study. Arch Perinat Med 17(4):229-234

37. Boswihi SS, Udo EE, Al-Sweih N (2012) Serotypes and antibiotic resistance in group B streptococcus isolated from patients at the maternity hospital, Kuwait. J Med Microbiol 61(1):126-131

38. Maeland J, Brakstad O, Bevanger L, Krokstad S (2000) Distribution and expression of $b c a$, the gene encoding the $\mathrm{c}$ alpha protein, by Streptococcus agalactiae. J Med Microbiol 49(2): 193-198

39. Persson E, Berg S, Bevanger L, Bergh K, Valsö-Lyng R, Trollfors B (2007) Characterisation of invasive group $B$ streptococci based on investigation of surface proteins and genes encoding surface proteins. Clin Microbiol Infect 14(1):66-73

40. Ho Y-R, Li C-M, Su H-P, Wu J-H, Tseng Y-C, Lin Y-J, Wu J-J (2007) Variation in the number of tandem repeats and profile of surface protein genes among invasive group B streptococci correlates with patient age. J Clin Microbiol 45(5):1634-1636

41. Zhao Z, Kong F, Gilbert GL (2005) Reverse line blot assay for direct identification of seven Streptococcus agalactiae major surface protein antigen genes. Clin Vaccine Immunol 13(1):145-149

42. Dore N, Bennett D, Kaliszer M, Cafferkey M, Smyth C (2003) Molecular epidemiology of group B streptococci in Ireland: associations between serotype, invasive status and presence of genes encoding putative virulence factors. Epidemiol Infect 131(2): 823-833

43. Poyart C, Tazi A, Réglier-Poupet H, Billoet A, Tavares N, Raymond J, Trieu-Cuot P (2007) Multiplex PCR assay for rapid and accurate capsular typing of group B streptococci. J Clin Microbiol 45(6): 1985-1988 